\title{
Photosensitive Hyperbranched Aliphatic Polyester Based on 2,2-dihydroxymethyl Butyric Acid
}

\author{
Fei $\mathrm{CAO}^{1}$, Li-Juan ZHANG ${ }^{2}$, Ling-Ling $\mathrm{MA}^{3}$, Meng-Meng $\mathrm{ZHOU}^{4}$, Jing $\mathrm{DU}^{5}$, \\ Ji-Jun XIAO ${ }^{6^{*}}$
}

College of Material Science and Engineering, Hebei University of Science and Technology, Shijiazhuang 050018, China

1'caofei777@aliyun.com, 2zlj0412@aliyun.com, ${ }^{3}$ malinglinghbkj@163.com,

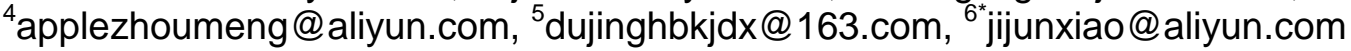

\section{${ }^{*}$ Corresponding author}

Keywords: Hyperbranched Aliphatic Polyester, 2,2-dihydroxymethyl Butyric Acid, Photosensitive Polyester, Degree of Branching.

\begin{abstract}
A new kind of photosensitive polyester based on the hyperbranched aliphatic polyesters has been investigated. The hyperbranched aliphatic polyesters (polymer A) with 0.69 of the degrees of branching (DB) was prepared from 2,2-dihydroxymethyl butyric acid. Followed by end-modified with maleic anhydride (MA), end-modified hyperbranched aliphatic polyesters (polymer B) with unsaturated end groups was successfully synthesized. The polymer properties were characterized by FI-IR, ${ }^{13} \mathrm{C}-\mathrm{NMR}$, GPC, TGA, respectively. The photosen-sitive hyperbranched aliphatic polyester (polymer C) based on polymer B, 4 wt\% Ltd.2-Hydroxy-2-methyl-1-phenyl-1-prop-anone (Darocur 1173) as a photoinitiator, and 2-Propenoicacid-1,1'-[(1-methyl-1,2-ethanediyl) bis[oxy(methyl-2,1ethanediyl)]] ester TPGDA(15wt\% relative to polymer B) as a reactive diluent was exposed for about $1 \mathrm{~s}(2.2 \mathrm{KW})$, and formed UV-cured polymer film and regarded as a promising photosensitive material.
\end{abstract}

\section{Introduction}

One of the exciting and promising developments in material science today is the design and synthesis of hyperbranched polymer materials [1] which are found to have potential applications in the field of functional materials, such as films[2], coatings[3], adhesive agents[4], modifiers[5] and so on. The candidate materials include polyurethane acrylate and hyperbranched polyester polyamide[6] etc. It is well known that hyperbranched polyester possesses a variety of unique proprieties such as good solubility, low viscosity, multivalence, and encapsulation effects, which mainly are caused by the branching and spherical architecture. In addition, it's well known that hyperbranched aliphatic polyester which mainly synthesis based on 2,2-dimethylol propionic acid (DMPA) as an AB2 monomer and trimethylolpropane (TMP) as a core moiety. Similarly, 2,2-dihydroxymethyl butyric acid (DMBA) is also a tri-functional compound containing a carboxylic group and two reactive primary hydroxyls, which is also regarded as an ideal compounds to be used to form new polymer. However, few papers about hyperbranched polymers from DMBA as AB2 monomer can be found.

In this paper, a novel hyperbranched polymer was prepared by the polycondensation of a AB2 type monomer, DMBA. The synthesis and characterization of these hyperbrabched polyester and end-modified polyester with carboxyl group and unsaturated $\mathrm{C}=\mathrm{C}$ double bonds were investigated, and its application for a photosensitivity polyester, which consists of these polyester and Darocur 1173 as a photoinitiator, and TPGDA as a reactive diluent, respectively. 


\section{Experimental}

\section{Materials}

2,2-dihydroxymethyl butyric acid (DMBA, more than $99.0 \%$ purity) was obtained from Jiangxi Nancheng Hongdu Chemical Technology Development Co., Ltd.2-Hydroxy-2-methyl-1-phe-nyl-1-prop-anone (Darocur1173) was supplied by Ciba-Geigy, Switzerland 2-Propenoicacid, 1,1'-[(1-methyl-1,2-ethanediyl)bis[oxy(methyl-2,1-ethanediyl)]] ester (TPGDA) was provided by TianJiTianjiao Co., Ltd. p-Toluenesulfonic acid (p-TSA, more than 99.0\% purity) was purchased from Lianyungang Ningkang Chemical Co.,Ltd..

\section{Synthesis of Hyperbranched Aliphatic Polyester}

Synthesis of Polymer A: Into a flask equipped with a nitrogen inlet, a thermometer and a reflux condenser, DMBA (22.2 g, $0.15 \mathrm{~mol})$ and p-TSA (1 wt \%) as a catalyst were added. The mixture was heated to $140^{\circ} \mathrm{C}$ and stirred at this temperature for $2 \mathrm{~h}$ under a stream of nitrogen. Then the nitrogen stream was turned off and the flask sealed and connected to a vacuum line for $2 \mathrm{~h}$, removing the water formed during the reaction.

Synthesis of Polymer B: In the second step, adequate MA, and hydroquinone $(0.007 \mathrm{~g})$ as inhibitor were added into the flask to react under a stream of nitrogen at $90^{\circ} \mathrm{C}$ for about $4 \mathrm{~h}$. Then acid value titration was used to pursue the reaction progress of polymer A and MA. Investigations on the acid value titration did not change any longer, which meant that anhydride groups had changed into carboxyl groups completely. At the desired acid value, the polymer B was synthesized.

\section{Photosensitivity}

Polymer C based on polymer B, $4 \mathrm{wt} \% 1173$ as a photoinitiator, and TPGDA(15wt\% relative to polymer B) as a reactive diluent was exposed for about $1 \mathrm{~s}(2.2 \mathrm{KW})$, and formed UV-cured polymer film and regarded as a promising photosensitive material.

\section{Characterization}

${ }^{13} \mathrm{C}-\mathrm{NMR}$ spectra of the synthesized hyperbranched polyesters was recorded on a Bruker Avance-500 MHz spectrometer (Bruker BioSpin, Switzerland). FT-IR spectra were obtained with Nicolet6700/ FT-Raman modules, American. Differential scanning calorimetry (DSC) was performed with a Seiko DSC 6200 instrument at a heating rate of $10^{\circ} \mathrm{C} / \mathrm{min}^{-1}$, in nitrogen. Thermal stability, as measured by $5 \%$ weight loss of the polymer samples, was determinded on a Seiko TG/DTA 6200 analyzer at a heating rate of $10^{\circ} \mathrm{C} / \mathrm{min}^{-1}$, in nitrogen. The molecular weights of the polymers were determined by gel permeation chromatograghy (GPC) relative to polystyrene standards, using tetrahydrofuran (THF) as an eluent.

\section{Results and discussion}

\section{IR Analysis}

The structures of polymers were identified by IR. In the IR spectra (Fig.1.), a new carbonyl absorption corresponding to an ester was observed at $1720 \mathrm{~cm}^{-1}$ while an absorption corresponding to carbonyl absorption at $1686 \mathrm{~cm}^{-1}$ observed in the monomer disappeared.

The FTIR spectrum of polymer B is shown in Fig.2, and compared with that of polymer A. A broader and considerably stronger absorption band at $1640 \mathrm{~cm}^{-1}$ for polymer B could be attributed to the $\mathrm{C}=\mathrm{C}$ double band. Hydroxy absorption band at $3200-3650 \mathrm{~cm}^{-1}$ become weaker. Anhydride absorption band almost disappears. 


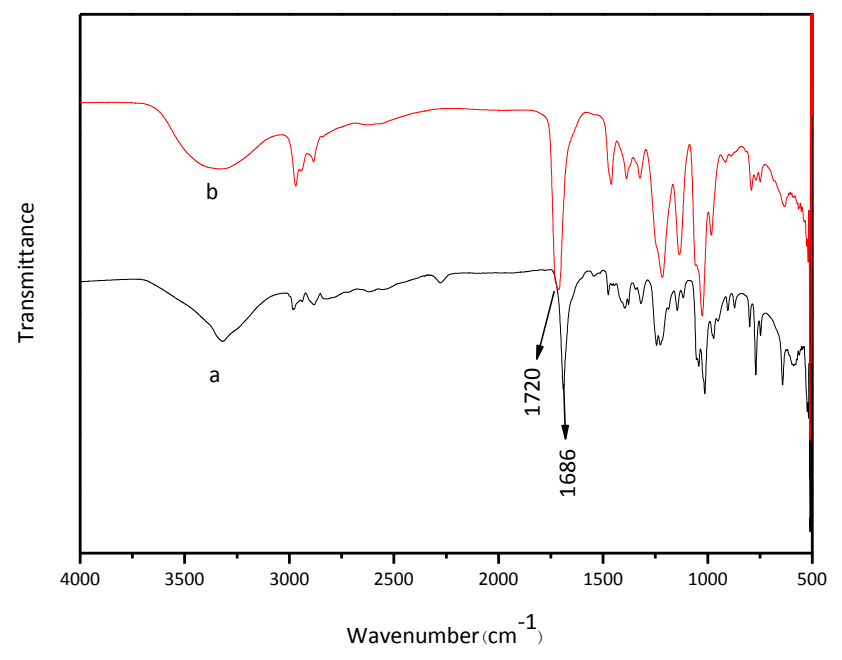

Fig.1 FTIR spectra of DMBA (a) and polymer A (b)

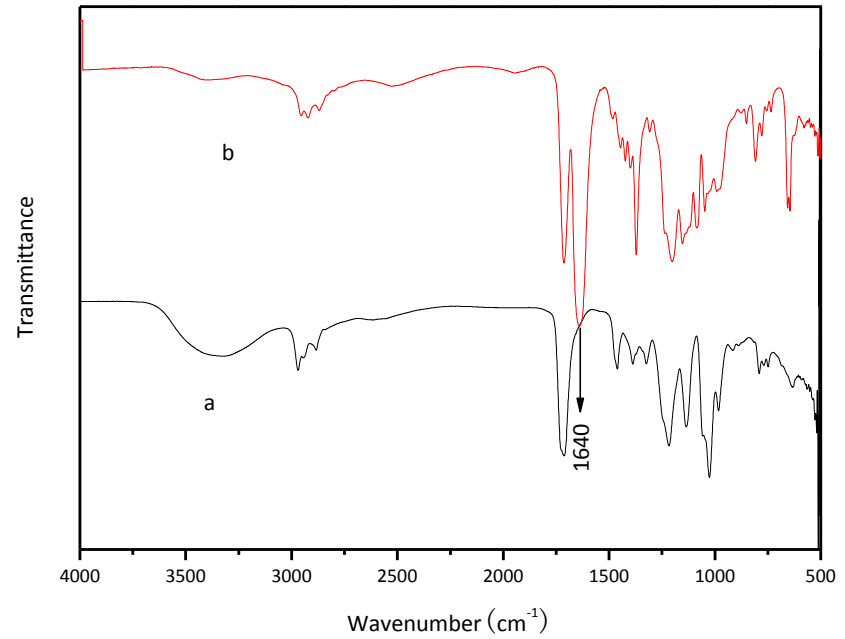

Fig.2 FTIR spectra of polymer A (a) and polymer B (b)

\section{NMR Analysis}

The ${ }^{13} \mathrm{C}$ NMR spectrum of the polymer A is shown in Fig.3. The signals of polymer A should be attributed to the quaternary carbon signals fractions of terminal, linear, dendritic and final dendritic unit at 54.058, 52.456, 51.631-51.672 and $50.497 \mathrm{ppm}$, respectively.

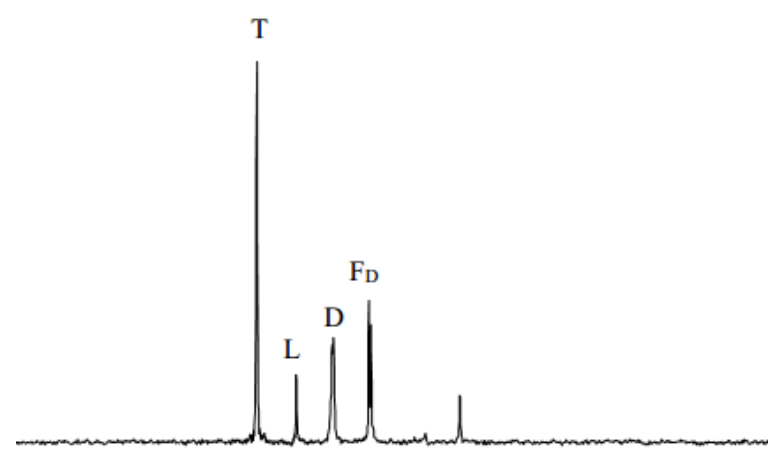

Fig. $3{ }^{13} \mathrm{C}$ NMR spectrum of the polymer A 
The hyperbranched structure is characterized by the average degree of branching (DB) and is one of the most important parameters of hyperbranched polymers, since it is correlated with the density of the hyperbranched structure and the location of the functional groups. The DB of hyperbranched polymers was given by Fréchet [7] .

$$
D B_{\text {Fréchet }}=\frac{D+T}{D+T+L}
$$

By integrated intensity of the peaks, so the estimated DB of polymer A from the integration ratio of T, L, D in ${ }^{13} \mathrm{C}$ NMR spectra can be calculated as 0.69 according to a definition given by equation (1).

As summarized in Table 1 , the weight-average molecular weight $\left(M_{\mathrm{w}}\right)$ of polymer $\mathrm{A}$ and $\mathrm{B}$ obtained by GPC were 1237 and 1646, respectively. The polydispersities (PD) were 1.227 and 1.232 , respectively.

Tab. 1 Molecular Weight of Polymer A and Polymer B

\begin{tabular}{cccc}
\hline Polymer & $M_{\mathrm{n}}$ & $M_{\mathrm{w}}$ & $M_{\mathrm{w}} / M_{\mathrm{n}}$ \\
\hline $\mathrm{A}$ & $1009^{\mathrm{a}}$ & $1237^{\mathrm{a}}$ & 1.227 \\
$\mathrm{~B}$ & $1338^{\mathrm{b}}$ & $1646^{\mathrm{b}}$ & 1.232 \\
\hline
\end{tabular}

${ }^{a}$ and ${ }^{b}$ determined by GPC in DMF and THE, respectively; polystyrene was used as the standard.

\section{Thermal Properties}

The thermal properties of polymer samples are listed in Table 2 .

Tab. 2 Thermal properties of polymer samples

\begin{tabular}{cccc}
\hline Polymer & $\mathrm{T}_{\mathrm{g}}^{\mathrm{a}}\left[{ }^{\circ} \mathrm{C}\right]$ & $\mathrm{T}_{5}{ }^{\mathrm{b}}\left[{ }^{\circ} \mathrm{C}\right]$ & $\mathrm{T}_{10}{ }^{\mathrm{b}}\left[{ }^{\circ} \mathrm{C}\right]$ \\
\hline $\mathrm{A}$ & 98.5 & 208 & 276 \\
\hline $\mathrm{B}$ & -1.3 & 160 & 203 \\
\hline UV-cured Polymer B & 43.76 & 208 & 312 \\
\hline
\end{tabular}

${ }^{\text {a }}$ Determined by DSC.

${ }^{\mathrm{b}}$ the temperature at which $5 \mathrm{wt} \%$ (T5) and $10 \mathrm{wt} \%$ of weight loss (T10) were determined by TGA in nitrogen at a heating rate of $10^{\circ} \mathrm{C} / \mathrm{min}-1$.

From Table 2, It can be seen that the $\mathrm{T}_{\mathrm{g}}$ of polymer A was greater than approximately $100^{\circ} \mathrm{C}$ in comparison to that of the polymer $\mathrm{B}$. The reason is caused by hydrogen bonds. In addition, it is clear that the $\mathrm{T}_{\mathrm{g}}$ of UV-cured Polymer $\mathrm{B}$ was much higher than that of polymer $\mathrm{B}$. This attributed to the fact that crosslinking of the double bond under the UV irradiation. Similarly, it is clear that the thermal decomposition temperature of UV-cured Polymer B was higher than that of polymer B. It means that the thermal stability of UV-cured Polymer B could be enhanced considerably by crosslinking of the double bond.

\section{Photosensitivity of Polymer}

After a series of optimization studies, a photosensitive polymer system consisting of polymer B, 1173 (4 wt \% of polymer B) and TPGDA(15wt\% relative to polymer B) was investigated by a UV exposure apparatus.

Hyperbranched polymer has more double bonds than traditional polymer, so that it can be rapidly crosslinked by exposing under UV light, indicating that the modified UV-curable hyperbranched 
polyester is a potential material for the application in the photosensitivity materials. The FTIR spectra of polymer B (a), and polymer B (b) with 1173 and TPGDA and UV-cured Polymer B (c) are shown in Fig.4. Clearly, the absorption band at $1604 \mathrm{~cm}^{-1}$ represents the $\mathrm{C}=\mathrm{C}$ double band stretching vibration, and the absorption band gradually weakened, which indicated that extensively $\mathrm{C}=\mathrm{C}$ double bonds were disappeared.

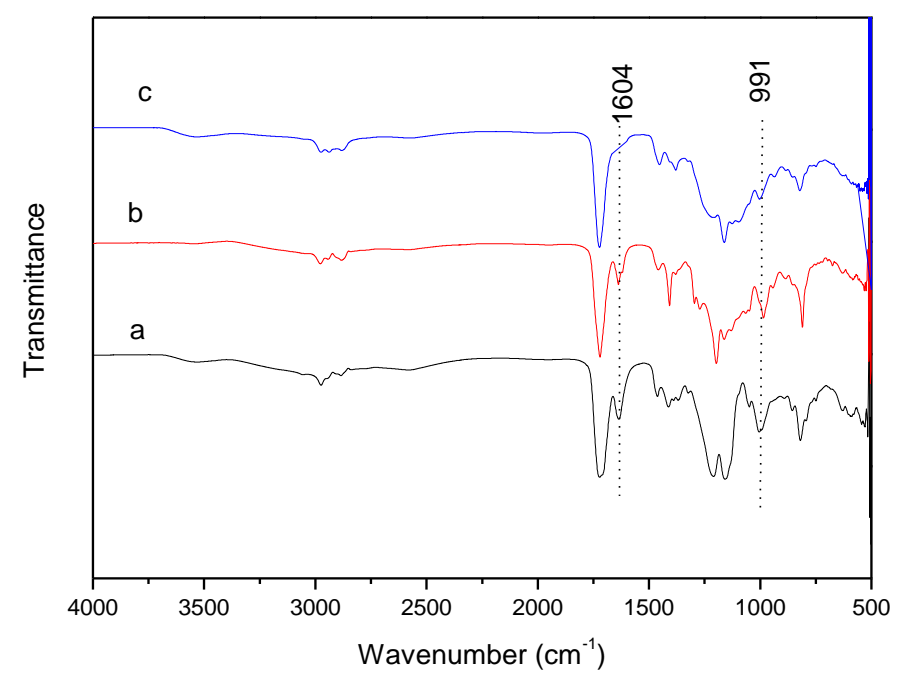

Fig. 4 FTIR spectra of Polymer B(a), Polymer C based on polymer B, Darocur 1173 and TPGDA(b) , UV-cured Polymer B (c)

\section{Conclusions}

Hyperbranched aliphatic polyester (polymer A) was prepared by self-polycondensation from symmetric $\mathrm{AB}_{2}$ monomer, 2,2-dihydroxymethyl butyric acid, in the presence of p-TSA as a catalyst. Polymer B was achieved by end-capping reaction of polymer A with MA to introduce the $\mathrm{C}=\mathrm{C}$ double bond at the termini. In addition, the $\mathrm{DB}$ of polymer $\mathrm{A}$ was calculated from ${ }^{13} \mathrm{C} \mathrm{NMR}$ measurement were 0.69. Photosensitive Polymer C based on polymer B, Darocur 1173 (4 wt $\%$ of polymer B) and TPGDA (15wt\% relative to polymer B) was exposed for about $1 \mathrm{~s}$ under a $2.2 \mathrm{KW}$ of full-length UV apparatus, and formed UV-cured polymer film and regarded as a promising photosensitive material.

\section{References}

[1] Y.H. Kim, W.O. Webster, Macromolecules, 25 (1992) 5561-5572.

[2] Y. Luo, W. Xin, G. Li, Y. Yang, J. Liu, Y. Lv, Y.J. Jiu, Memb. Sci. 30(2007) 183-193.

[3] A.T.M. Rolf, V. Benthem, Prog. Org. Coat. 40 (2000) 203-214.

[4] H. Liu, C.E. Wilen, M. Skrifvars, Reaction of epoxy resin and hyperbranched polyacids, J. Polym. Sci. 38 (2000) 57-65.

[5] D. Schmaljohann, P. Po1tschke, R. Ha1ssler, Blends of Amphiphilic Hyperbranched Polyesters and Different Polyolefins, Macromolecules . 32 (1999) 6333-6339.

[6] L.J. Hobson, A.M. Kenwright, W.J. Feast, Chem. Commun. (1997) 1877.

[7] C.J. Hawker, R. Lee, J.M. Fréchet, J. Am. Chem. Soc. 131(1991) 4583-4588. 